\title{
La escuela zapatista: educar para autonomía y la emancipación
}

\section{The zapatista school: educating for autonomy and emancipation}

Dr. César Silva Montes es profesor e investigador de la Universidad Autónoma de Ciudad Juárez (México) (cesilva@uacj.mx) (http://orcid.org/0000-0003-0531-2911)

Recibido: 2018-03-31 / Revisado: 2018-11-05 / Aceptado: 2018-11-20 / Publicado: 2019-01-01

\section{Resumen}

En el presente artículo se expone el desarrollo de la escuela del movimiento zapatista que construye su propuesta educativa desde la comunidad, basados en la sabiduría ancestral para ligarla con el pensamiento contemporáneo. El fin de la educación zapatista es formar generaciones en la práctica de la autonomía y autogobierno para conservar su dignidad indígena. La experiencia no es un modelo ni cabe en otras corrientes pedagógicas. Aunque original, en su base pueden distinguirse las ideas de Paulo Freire de alfabetizar para leer el mundo y transformarlo. En este sentido, la escuela zapatista es anticapitalista y no se rige por las normas del mercado que expide títulos para cambiarse por dinero; no es mercancía pues nadie paga por aprender y a nadie cobra por enseñar; tampoco es un aparato de Estado, porque cada pueblo determina los contenidos curriculares para usar el conocimiento y desarrollar la colectivización del campo, impulsar cooperativas y las tiendas comunales. A diferencia de la tendencia global de escuelas que promueven la mentalidad emprendedora, del mérito y de autoempleo, en la educación zapatista se aspira a que los jóvenes sirvan a su pueblo, sean solidarios y que los conocimientos no impliquen la jerarqui- zación social. La vivencia en una comunidad zapatista y las entrevistas con promotores de educación, permiten entender que la escuela zapatista sigue en construcción y debe evitar la burocratización y la homogeneización propias del capitalismo.

Descriptores: Escuela, zapatismo, educación, comunidad, autonomía, emancipación.

\begin{abstract}
The present article exposes the development of the school of the Zapatista movement, which builds its educational proposal from the community, based on ancestral wisdom to link it with contemporary thought. The aim of the Zapatista education is to train generations in the practice of autonomy and self-government in order to preserve its indigenous dignity. This experience is not a model, nor does it fit into other pedagogical movements. Although it is original, Paulo Freire's ideas can be distinguished such as his alphabetize to understand the world and transform it. In this sense, the Zapatista school is anti-capitalist and is not governed by the rules of the market that grants titles to students to earn for money; it is not merchandise because nobody pays to learn and nobody charges for teaching; it is not
\end{abstract}

Forma sugerida de citar: Silva Montes, C. (2019). La escuela zapatista: educar para autonomía y la emancipación. Alteridad, 14(1), 109-121. https://doi.org/10.17163/alt.v14n1.2019.09 
part of the State either, because each town determines the curricular contents to use the knowledge and develop the collectivization of the field, promote cooperatives and the communal stores. Unlike the globalization trend of schools that promote the entrepreneurial mentality, merit and self-employment; Zapatista education aspires that young people serve their people, be supportive and that knowledge does not imply social

\section{Introducción}

En este artículo se presenta un acercamiento a la experiencia educativa zapatista. En principio, se establece que la senda hasta el 2018, no corresponde a la lógica de ligar la educación con los objetivos del Gobierno. Es un intento por superar los postulados de Louis Althusser (2003) que observa a la escuela como un aparato ideológico para reproducir los valores de los grupos en el poder. Una evidencia es la inexistencia de unicidad en el currículo y métodos de enseñanza de cada comunidad. La enseñanza busca un aprendizaje más autónomo, activo, creativo y liberador; en el cual importa más la dignidad que la comercialización de los títulos profesionales. Los criterios de calidad y evaluación relacionados con la eficiencia y el control de la productividad industrial no existen en su escuela. No es una educación para promover la ideología emprendedora e individualista del capital humano como solución a todos los problemas. Al contrario, es una propuesta construida desde las comunidades para emanciparse del capitalismo y, según el zapatismo, de sus cuatro ruedas: explotación, despojo, represión y desprecio.

El análisis surgió desde la convivencia en una comunidad de Acteal con la asistencia a la escuelita zapatista, de la revista Rebeldía, de algunos comunicados del Subcomandante Marcos y de textos de investigación y análisis sobre la práctica educativa zapatista. En la estructura del texto se presentan los fundamentos de la formación zapatista y una discusión sobre la escuela capitalista actual. Enseguida se pretende caracterizar el sentido de la enseñanza zapatista, que incluye un hierarchy. The experience in a Zapatista community and the interviews with promoters of education, allow us to understand that the Zapatista school is still under construction and must avoid the bureaucratization and homogenization proper to capitalism.

Keywords: School, zapatismo, education, community, autonomy, emancipation.

breve recorrido histórico de la educación popular en América Latina. Enseguida se detalla la experiencia de la escuela zapatista que diseña su currículo y contenidos desde cada comunidad. Cierra el artículo con las reflexiones de su propuesta y algunas de sus dificultades. Se destacan sus rasgos de una educación pública como un derecho, que no es una mercancía y se orienta por los anhelos de autonomía del movimiento zapatista.

\section{La escuela zapatista en el contexto de la globalización}

La educación zapatista surgió después de su movimiento armado y del establecimiento de 38 municipios autónomos en 1994, como un hecho político para formar en la población la conciencia para el autogobierno, la diferencia, la equidad de género, el cuidado de sus territorios, la independencia económica y la autosuficiencia alimentaria. En la Tercera Declaración de la Selva Lacandona el Ejército Zapatista de Liberación Nacional (EZLN, 1995) convocó a un Movimiento de Liberación Nacional para diseñar una nueva Constitución y un gobierno de transición, y evitar la venta del ejido a particulares. Demandó un programa económico en favor del colectivo obrero y del campesinado, principales productores de riqueza, y por la autonomía de los pueblos indígenas que reconozca su organización social, cultural y política. Desde su aparición, en la Primera Declaración de la Selva Lacandona (EZLN, 1994) el zapatismo expresó su renuncia a la toma del poder, a ser vanguardia, a cobrar por gobernar, y expresaron que desa- 
parecerían cuando se eliminen las causas de su insurrección.

Para entender la práctica de la escuela zapatista, conviene distanciarse de la retórica que considera a la escolarización como instrumento para desarrollo material y social de los países, sobre todo desde los sesenta del siglo XX. En 2018 a la escuela que certifica para el mundo del trabajo se le ostenta como un fetiche para la solución de todas las problemáticas. Ante la ausencia de evidencias empíricas de que educación es igual a progreso económico y humano, renace la idea de Ivan Illich (1989) de desescolarizar el mundo. En México cada nuevo gobierno implanta reformas educativas y poco cambia. No falta el comentario jocoso de que la recurrencia de tales reformas muestra su inutilidad (Tyack \& Cuban, 2001). Por ejemplo, la modificación en la ley sobre condiciones laborales para el magisterio en 2012 se justifica porque supone que mejorará el trabajo docente y del funcionamiento de la escuela para lograr calidad educativa, y así resolver los conflictos generadas en la sociedad, todavía, llamada capitalista.

En el siglo XXI, en medio de los cantos alegres del éxito de la globalización, persiste el despojo y la explotación de la naturaleza; el lucro es el eje de la economía y no para el servicio de las familias, las trasnacionales controlan a los países y los presidentes se vuelven gerentes; la desigualdad de la repartición del ingreso se acentúa; la biotecnología y la informática aumentan el desempleo (Silva, 2018). ¿Cómo resolverlo? Dirá la retórica oficial: "formando capital humano de alta calidad en las escuelas". Se cree que la escuela con materias como orientación vocacional, educación sexual o vial, podrá solucionar la desvinculación perfil de egreso-trabajo, los accidentes carreteros o las enfermedades venéreas. Sin faltar la promoción de valores universales afines al capital, sintetizado en el perfil de sujetos emprendedores y capaces de autoemplearse. Estrategia adecuada en el contexto de recorte de puestos de trabajo en los sectores privados y gubernamentales, más el incremento de las polí- ticas de subcontratación laboral que disminuye prestaciones, sólo queda la alternativa de laborar por cuenta propia.

Así lo postula el Gobierno mexicano en el Programa Sectorial de Educación 2013-2018, Estrategia 1. Democratizar la Productividad:

5. Promover y fomentar la vocación emprendedora (...) como una opción profesional (...) buscando sinergias (...) de formación de capital humano (...) 15. Fortalecer el sistema nacional de competencias laborales (...) (certificando) iniciativas productivas, educativas, laborales y de capacitación (pp. 52-53).

El discurso hegemónico en las escuelas mexicanas renueva la noción de aparato ideológico de Althusser (2003), porque la escuela reproduce los intereses del Estado. ¿Acaso el currículo en competencias no corresponde a las demandas del empresariado globalizado? La calidad en educación, ¿se mide con los parámetros de la producción o con los criterios cualitativos no mensurables de la cotidianidad del aula? ¿O la evaluación al profesorado escapa de los indicadores de eficiencia y productividad propios de la industria que manufactura a destajo? ¿O el predominio del modelo de enseñanza centrada en el estudiante, poco novedosa si se compara con la escuela nueva?

Pero no todo está perdido. Existe una pedagogía crítica que ubica el problema de la educación en lo político, no en lo técnico. Después de analizar la ideología que subyace en los procesos de enseñanza, entienden a las escuelas como espacios de resistencia y generación de proyectos comunitarios alternativos al poder del Estado (Giroux, 1992; Apple, 1997). Postulan que la renovación de la enseñanza no puede separarse del replanteamiento social, con base en las ideas de Freire se intenta una educación crítica y emancipadora, porque la dominación no es total. Y el profesorado debe ser un intelectual transformador (Giroux, 1997). El análisis institucional aporta la noción de autogestión pedagógica que significa la renuncia del profesorado a transmitir 
mensajes en el aula y aspira a que el estudiantado decida los métodos de aprendizaje (Lapassade, 1977). Por último, el concepto de resistencia en la escuela, espacio de contradicción y de conflicto, imagina que pueden generarse prácticas culturales alternativas y/o de oposición a la hegemonía.

Las antípodas permiten preguntarse si alguna vez la educación sirvió a la sociedad. En la historia de México aparece el ideal de la revolución de 1910 de impulsar un desarrollo nacional soberano e incluyente. En el México rural, el profesorado de entonces difundió conocimientos agrícolas prácticos según la región y se intentaba resolver los problemas de la comunidad (Vaughan, 1997). También se enseñaba curtiduría, canciones populares, educación física y danza. La imagen de aquellos profesores era de profesionales, honestos y comprometidos con una educación nacional heredera del principio: la tierra es de quien la trabaja. No obstante, las misiones culturales impulsadas por José Vasconcelos que bajo la noción de civilización para integrar al sector indígena, se trató de despojar a los pueblos originarios de su identidad.

Saltando a los sesenta, en el mundo hubo experiencias como la del Instituto Experimental de Oslo que cuestionaron la lógica de la escuela burocrática y plantearon: asistencia no obligatoria a las clases y no al pase de lista; programa y métodos de enseñanza discutido entre alumnado y docentes; libertad de enseñanza. La propuesta surgió de estudiantes de secundaria reprobados que decidieron fundar una escuela no tradicional. La enseñanza sería libre y sin la opresión de los reglamentos, buscando formar personas autónomas y democráticas (Jörgensen, 1997). Así de sencilla sería la aspiración de una educación opuesta a la lógica de reproducir el pensamiento único y de obediencia a las reglas, porque la escuela sola no puede modificar los males sociales. En otras palabras, sin reforma social no hay reforma educativa; o viceversa.

Para cerrar la sección, desde 1875 Marx escribió que la educación no es igual para todas las clases sociales. Ironizó la factibilidad de obligar a la burguesía a estudiar en la modesta escuela pública, la única accesible al proletariado y al campesinado. Para Marx (1986) el Estado no debería encargarse de la educación popular, más allá de la entrega de recursos y normar las condiciones del personal docente, sino que el pueblo debe educar al Estado. Pareciera que tales deliberaciones las entendieron las y los zapatistas.

\section{Los intentos por definir la educación zapatista}

Una de las propuestas para caracterizar la enseñanza zapatista es ligarla con la educación popular y el pensamiento de Paulo Freire, cuando plantea la alfabetización para conocer el mundo, nombrarlo, para que la gente aprenda a decir su palabra e intente transformarlo. Es una educación para el pueblo en busca de la emancipación de cualquier tutela, subordinación, dependencia o servidumbre. No es el pueblo en abstracto, se refiere a las personas que viven en la marginación social, política y económica. Para Freire (1997) "la rebeldía es un punto de partida indispensable" (p. 77) contra la injusticia. En el caso indígena, para salir de la opresión, la discriminación, incluso el racismo, que han padecido en México. Por esto, sin ambigüedades, la educación zapatista aspira a una escuela con una pedagogía política para la paz, la formación ciudadana en aras de construir el poder comunitario, el autogobierno y una educación no mercantil. Lograrlo, implica que los contenidos y las didácticas surjan de la gente para formarse con, por y en la comunidad.

En América Latina la educación popular tiene una larga tradición. Según Gómez \& Puiggrós (1986) las prácticas pedagógicas nacionalistas y populares en el continente, existen, cuando menos, desde 1935. En su recuento señalan que Lázaro Cárdenas en México promovió esta educación. En 1946 en Guatemala se instituyeron las Misiones Culturales Ambulantes para llegar a toda la nación. Se difundió el culto a los símbolos y valores patrios, el conocimiento de la Constitución y el sentido de la revolución. 
Además, se promovió la higiene, la prevención y cura de enfermedades, nociones sobre embarazo y parto, las técnicas agrícolas y la rotación de cultivos. Se ocuparon de impulsar el deporte, la música, el cine, el teatro. Aunque no tuvieron el efecto esperado, las Misiones se conformaron con un equipo multidisciplinario (en boga actualmente, como si fuera una novedad): un maestro, un estudiante de medicina del último año, un perito agrícola, un oficial del ejército y una intérprete indígena.

En el recorrido, Gómez y Puiggrós (1986) destacan las experiencias de Bolivia (1938 y 1954), Colombia (1947), El Salvador (1974), Cuba (1960) y Nicaragua (1980). Afirman que en 1961 se elaboró el discurso de la pedagogía de la liberación; y de 1976 a 1983 la escuela fue un espacio de lucha contra las dictaduras. Se resaltan las críticas a la enseñanza que conforma personas obedientes, individualistas, la ideología capitalista y la dependencia científica, tecnológica, cultural y económica de Latinoamérica. La alternativa se genera desde la comunidad y la sociedad marginada, por una educación gratuita, por la defensa de la cultura y la igualdad de la mujer. El énfasis de la educación popular fue lo étnico y lo indígena como en los países andinos. Las fuentes que conforman esta corriente, entre otras, son la teología de la liberación, la investigación-acción y la comunicación popular, según Gómez y Puiggrós.

En este contexto, para Torres (2012) la escuela zapatista, que se autonombra de educación verdadera, retoma los postulados de Freire sobre humanización, la liberación de los opresores, la naturaleza política de la enseñanza y su perspectiva de transformar las estructuras de poder. Es una educación para la praxis, con heterogeneidad lingüística y cultural, con una pedagogía crítica y radical. En consecuencia, la educación zapatista es de participación colectiva, reivindica el ser indígena, establece lazos de solidaridad y de responsabilidad compartida en sus pueblos. El currículo escolar se diseña desde la comunidad y en congruencia con las deman- das zapatistas de la rebelión de 1994, recogen el conocimiento oral de los ancianos y las ancianas. Los promotores y promotoras de educación preparan el material didáctico de los cuentos, guías y libros, en colaboración con asesores externos.

Otra caracterización de la escuela zapatista es de Baronnet (2010, 2011a, 2015), quien la concibe con autonomía indígena, relaciones horizontales en la educación, la democratización de la gestión escolar, una enseñanza contextualizada afín a las identidades sociales, étnicas y políticas de los pueblos. Son escuelas en resistencia y emancipadoras de acuerdo con un proyecto político-regional en cada municipio autónomo, basada en principios pedagógicos de la praxis y el sentido común. No existe un modelo de enseñanza de programas de estudio, sino en construcción constante. Baronnet coincide con Muñoz (2004) en que los encargados de la educación en talleres integran las demandas de conocimiento en grupos de reflexión y análisis en las comunidades que son ratificadas por las asambleas y las autoridades del municipio. De ahí la denominación de educación verdadera, porque se desarrolla en contra de los valores y conductas colonialistas. Se trata de rescatar la memoria histórica tradicional de los pueblos y la cultura con la participación de las familias. Esto permite que la escuela zapatista no sea la instancia principal de socialización política, porque en la cotidianidad los niños y las niñas participan en actos públicos, asambleas y movilización social. Por último, para Baronnet (2011a) la ideología educativa se integra con el pensamiento de izquierda como el Che Guevara y Friere; y en la docencia siguen algunas prácticas pedagógicas activas de Celestin Freinet.

No es interés expresar un modelo de la educación zapatista con este breve recuento. Sin embargo, se detectan principios políticos y filosóficos como la educación popular, la idea emancipadora de Freire, el currículo delineado desde cada comunidad, la educación como un asunto de las familias, la escuela, las autoridades y el EZLN. La relación en el aula es horizontal, no autoritaria y activa. Es una formación teórica- 
práctica pues combina la escuela con el trabajo en la comunidad; es una educación no mercantil, porque no se paga por enseñar ni por aprender; tampoco se venden títulos para intercambiarse en el mercado de trabajo.

\section{La experiencia educativa zapatista}

Desde las voces de Doroteo, Abraham, Artemio y Gerónimo integrantes de las JBG y de la administración de los pueblos, se establece que el sistema Educativo Autónomo Zapatista de Liberación Nacional (SERAZLN) inició en 1997 en La Realidad, en el Municipio Autónomo Rebelde Zapatista Libertad de los Pueblos Mayas (EZLN, s.f.a). Desde antes de 1994 entendieron que la educación oficial y sus métodos no eran compatibles con sus afanes de autonomía, pues se trataba de instituir una educación del, para y por el pueblo. Para empezar, no había receta ni recursos. Tampoco estaban conformes con el trabajo del profesorado enviado por el gobierno. En San Juan de la Libertad optaron por organizar una secundaria con personas que estudiaron la secundaria o la preparatoria, y hasta alguna maestra. El fin fue aprovechar que con las niñas y los niños egresados de la primaria se formarían los nuevos educadores y educadoras. Entonces el grupo Escuelas para Chipas apoyó la construcción de aulas y desembocó en las Escuelas Secundarias Rebeldes Autónomas Zapatistas (ESRAZ).

Después de reflexionar, decidieron que las matemáticas, la lectura y la escritura no se podían cambiar por su alcance universal. Pero en historia si modificaron los temas. Incluyeron la trayectoria del EZLN y de otros movimientos sociales. Luego se preguntó a los padres y madres de los pueblos qué necesitaba aprender la niñez zapatista en cada comunidad. Otros cambios de contenido y nombre se realizaron en español y ciencias naturales. Se renombraron lenguas $\mathrm{y}$ vida y medio ambiente, respectivamente. Se agregó "integración" a diversos tópicos que no abarcaran las asignaturas, como las 13 deman- das de su levantamiento. También la noción de materia se sustituyó por área. En el municipio de Ricardo Flores Magón elaboraron el "documento de educación verdadera”, entendida como rescatar los conocimientos y saberes del pueblo, conocer su historia. Con el apoyo de la sociedad civil de compatriotas e internacionalistas, se elaboraron los planes y programas de estudio y los materiales didácticos. Enseguida se plantearon cómo comprobar el aprendizaje del niño o la niña. Acordaron que en la escuela autónoma eran prescindibles las boletas de calificación y los certificados de estudio. Asimismo, descartaron los exámenes porque el aprendizaje se verificaría en el desarrollo de su trabajo en un cargo.

Otro desafío para la educación autónoma fue la formación de promotores y promotoras de educación, que fue posible con la colaboración del grupo Semillitas del Sol, de la Ciudad de México. La capacitación dura seis meses, se aplica una evaluación y si alguien no muestra el conocimiento pleno del área, estudian dos meses más. Luego se creó el Centro de Formación compañero Manuel. Se les llamó promotores porque no asistieron a la escuela normal a estudiar para impartir clases. Con la creación de las Juntas de Buen Gobierno (JBG) ${ }^{1}$ en agosto de 2003, se consolidó la estructura del SERAZLN y aumentó la construcción de escuelas. En primaria se enseña en tres niveles y aprenden a leer y escribir. En el municipio Che Guevara los estudiantes y las estudiantes salieron de sus comunidades y vivieron un periodo de estudio más intenso.

Para el zapatismo la autonomía de la escuela empieza con la independencia económica, ideológica y del personal docente del gobierno mexicano. La construcción de su sistema educativo en lo pedagógico y material deriva de la solidaridad de los pueblos del mundo. El fin y sentido de la escuela zapatista no es la capacitación para el trabajo, sino comprender su historia, su cultura y de su cosmovisión. El anhelo consiste en formar profesionistas indígenas y no indígenas para ayudar a sus comunidades, encaminados a fortalecer la construcción de su 
autonomía política, económica, social y cultural. En síntesis: "Podemos educar con los alumnos y alumnas -que nos educan- para poder educarnos de quienes somos para la vida y así construir a esos muchos mundos que soñamos todos y todas" (SERAZLN, s. f., parr. 2). Las escuelas reciben apoyo económico y las administran y vigilan las autoridades de los pueblos.

Los contenidos de la educación zapatista se diseñan con base en los propósitos que generaron su rebelión: salud, techo, tierra, trabajo, alimentación, educación, independencia, democracia, libertad, justicia, cultura, información y paz (EZLN, 1994). El equivalente del currículum de la educación zapatista se completa con el conocimiento cotidiano de sus comunidades y la propuesta de cada uno de los temas necesarios para que aprendieran sus hijos e hijas. En las clases se estudia la realidad del país, las maneras de convivencia y la lengua de los pueblos. Como en el SERAZLN se respetan las diferencias, las áreas de conocimiento varían según la comunidad y se dividen en: lenguas, matemáticas, ciencias naturales, ciencias sociales, humanismo y producción, que abarca el cuidado del medio ambiente, con la misma cantidad de horas de estudio a la semana. En secundaria se examinan el desarrollo de sus pueblos y de los acontecimientos globales.

En La Garrucha, en la selva tzeltal, en 2008 se renovó la dinámica educativa al constituirse la escuela Semillita del Sol, organizada en tres niveles. Inician enseñando a los niños y las niñas a escribir y dibujar, pasando por comprender las demandas del movimiento zapatista, hasta analizar comunicados, denuncias, organización de su gobierno, los motivos de su lucha y el logro de su autonomía. Se incluye el conocimiento de la sustentabilidad del territorio. Un tema transversal, como es común en los currículos actuales, es la agroecología porque es una preocupación en las comunidades.

El lema de las escuelas zapatistas: "Que haya una educación real y que sea para todos", bajo el principio de formar al educando con la conciencia colectiva, didácticas de aprendizaje grupales y no directiva. Es un ideal de aprender en la libertad, orientado a que cada niño y niña alcance el conocimiento en colaboración con los promotores y promotoras, en un ambiente sin maltratos. Si la educación zapatista es parte de su resistencia y la difusión de su filosofía zapatista, por tanto, se pretende que el alumnado reflexione "(...) sobre la lucha, pues el objetivo principal que nos planteamos es que (...) tengan una visión diferente de la vida. Que no hagan una vida individualista" (Muñoz, 2004, p. 10). $\mathrm{Al}$ egresar se les pide a las jóvenes y los jóvenes que apoyen las tareas de agroecología, en los centros de comercialización, en las farmacias o alfabetizando. El interés formativo de la escuela se enfoca a servir al pueblo, no para trabajar en favor del capitalismo; tampoco para diferenciar entre quien sabe más y eludir la jerarquización propia de la educación capitalista.

Un avance de la escuela zapatista es la asistencia de las niñas a educarse y combatir la marginación. En los certificados de la ESRAZ viene la leyenda: "Por lo que nuestro Sistema Educativo le reconoce su esfuerzo, sus aportes a la lucha de resistencia y le invita a compartir con nuestros pueblos, lo que el pueblo le ha dado (...) ¡Por una educación liberadora, (...) científica y popular! Me pongo al servicio de mi pueblo" (Marcos, 2003, parr. 21). Hay dos evaluaciones: A (área aprobada) y ANA (área no aprobada). La escuela es gratuita y los comités de educación procuran que cada estudiante cuente con un cuaderno y un lapicero.

Para una educación no diferenciadora no se necesitan calificaciones, exámenes ni certificaciones. Lo importante es que la juventud zapatista aplique en su vida cotidiana y comunitaria sus aprendizajes, sus capacidades para leer y escribir. Por supuesto, distintas a las competencias surgidas de la industria que en las escuelas modelan el perfil de egreso para la producción toyotista (Silva, 2016). Por cierto, competencias decidas desde Europa a través del proyecto Tunning, distantes de los saberes y contenidos decididos desde la comunidad congruentes con 
su comprensión de la realidad. Las competencias lectoras y de escritura son útiles para que las mujeres desarrollen sus tareas en las JBG. Para gobernar no se requieren títulos ni grados académicos. Innecesarios para llevar la contabilidad de los gastos de la JBG o en la formación de las parteras, yerberas y hueseras. También les sirve a las mujeres cuando trabajan de coordinadoras de zona o capacitadoras de educación.

\section{Los hombres y las mujeres que hacen posible la enseñanza no mercantilista}

Para sustentar que la educación zapatista no es objeto de comercio, se exponen los comentarios de mi entrevista con dos promotores y una promotora de educación de Oventik. Además, las conversaciones con una familia de Acteal durante mi asistencia a la escuelita zapatista en enero de 2014. El EZLN convocó a convivir con sus bases de apoyo en sus comunidades para conocer a través de sus enseñanzas su pensamiento y su libertad, los aciertos, errores, problemas y soluciones, los avances y los obstáculos de su autonomía (Moisés, 2013). También el EZLN elaboró "cuadernos de texto" para los asistentes estudiáramos cómo han construido su autogobierno, la participación de las mujeres en la política, sus avances en la salud y educación. Las familias nos proveyeron de habitación y alimentos. Compartimos sus actividades productivas, reuniones políticas y platicamos de su resistencia.

Así, la asamblea comunitaria elige a quienes educan en la escuela zapatista y serán cesados según el criterio del comité de vigilancia. Los llaman promotores y promotoras de educación, porque no se formaron en alguna normal oficial, sino con las personas con capacidades docentes de sus pueblos. La aceptación para enseñar es voluntaria y es parte de un compromiso de educar para la liberación y la lucha. No recibe plazas y deberá trabajar en la milpa, porque se compromete a trabajar para el sostenimiento de la escuela (Baronnet, 2011b). Ser promotor o promotora de educación no es una vía para alcanzar solvencia económica, ni privilegios en la comunidad. Como afirma Johnny, promotor de educación: “(...) Nosotros trabajamos por conciencia nada más y la conciencia es la que ganamos... no cobramos nada, pues es libre" (Hijar, 2008, p. 147).

La manutención de los promotores y las promotoras se basa en que la comunidad los ayuda con alimentos, ropa o trabajan en las parcelas de sus familiares durante las vacaciones, en la elaboración de artesanías o la crianza avícola. Por tanto, educar implica la dedicación para divulgar el proyecto político, social y económico zapatista que busca la autonomía y el autogobierno. En suma, no se trabaja por la remuneración económica capitalista. Como señalaron Marx y Engels (1985), la burguesía con el dinero enterró la dignidad personal convirtiendo en asalariados al médico, al jurista, al poeta, al sacerdote, al hombre de ciencia.

En la ESRAZ los promotores y las promotoras coordinan la escuela en colectivo y de manera rotativa, ellos y ellas deciden las actividades escolares con base en el consenso, entre otras, cómo trabajar. Gracias a su autonomía determinan las cuestiones pedagógicas y administrativas. Una forma de enseñanza es a través de las preguntas generadoras, tomadas de Freire, y del cuestionamiento sobre la realidad surgen temas a desarrollar en el aula. En grupo el estudiantado delibera cómo responder a las preguntas para aprender, apoyados en la revisión de documentos, en la observación de su entorno o desarrollando experimentos.

En su perspectiva global, el Centro de Español y Lenguas Mayas Rebelde Autónomo Zapatista (CELMRAZ), acoge a personas que deseen aprender el tzotzil y el español. Sin altas colegiatura ni limitar la oferta de idiomas al inglés como lengua franca. Como una actitud solidaria, sólo se pagan tres días de salario mínimo del país donde residen y trabajan, más 150 pesos para la alimentación. Además, otorgan, comidas y el hospedaje, porque el principio de 
CELMRAZ es: "No hacemos de la lengua una mercancía más" (s.f., parr. 2).

\section{La organización de las clases y la formación para la autonomía política}

Respecto a las clases, la pedagogía zapatista establece las actividades de acuerdo con estudiantes y promotores, los horarios son flexibles y no se restringe a un espacio físico. Las sesiones buscan la construcción colectiva y la animación de actividades. En consecuencia, se exhiben videos de la lucha zapatista; se visitan los espacios en donde se desarrollan proyectos económicos; se promueve la convivencia y la alegría con canciones, bailes y debates; se invita a labores voluntarias en la biblioteca o en la siembra. Se impulsa la conversación y la reflexión en colectivo.

El fin es lograr la autonomía que implica para el zapatismo, como lo sintetizan Adamovsky et al. (2011), la forma de hacer política con independencia de la clase política y sus partidos, rechazando el autoritarismo y las relaciones de dominio de la vida cotidiana; la diversidad que cuestiona la hegemonía de cualquier tipo; a favor de la autogestión y la autodeterminación; y la emancipación del capital. Se resisten a dejar ser pueblos indígenas y buscan dejar ser colonias de los finqueros. En su forma de gobierno las comunidades indígenas zapatistas se guían por el mandar-obedeciendo. El pueblo manda y las autoridades obedecen, no se paga por gobernar y los puestos son rotativos y elegidos por las asambleas. López (2011) condensa la exigencia de autonomía del movimiento indígena: demandan derechos colectivos para sus pueblos; la transformación del Estado; reclaman sus territorios y la propiedad de sus recursos naturales; el reconocimiento de sus formas de gobierno y la administración de justicia propia; el respeto a su cultura.

En síntesis, el zapatismo se propone educar para la liberación a partir de las vivencias de las comunidades. La estructura de las escuelas en niveles, no implican la división rigurosa por edad. Esto permite una convivencia en las aulas de estudiantes de diferentes edades y refuerza el principio de Freire de que nadie educa a nadie y nadie se educa solo. La educación zapatista pretende que los jóvenes y las jóvenes de las comunidades se identifiquen con su historia pasada y presente indígena, aceptar la diferencia entre las personas y preservar su lengua. Se trata de educar para formar en la autonomía una nueva forma de hacer política, la democracia directa y rechazar que la tierra es un artículo para venderse al mejor postor.

\section{Reflexiones sobre la escuela zapatista}

La educación zapatista cumple con tres conceptos ausentes en la globalización de mercado: 1) es pública, porque se diseña desde los pueblos y es un derecho; 2) es libre, pues no depende del Estado ni de las trasnacionales del dinero o de la cultura para diseñar su currículo, ni certifican al estudiantado para ser un expediente más en los archivos de la burocracia escolar; 3) es gratuita, nadie paga por asistir a la escuela, ni nadie cobra por enseñar, así la educación no es una mercancía. No corresponde al capitalismo académico que en resumen significa: realizar actividades en las universidades y la planta académica para responder a la economía basada en el conocimiento, y quienes investigan deben conseguir financiamiento para sus estudios, en general, conforme a las ciencias y disciplinas afines al mercado. Así, las humanidades se vuelven ciencias innecesarias para la competitividad, la productividad y el crecimiento económico. El conocimiento es un bien para comercializarse y generar ganancia, como con las patentes (Maldonado, 2016).

Un aporte de la escuela zapatista es que no sigue la linealidad de los grados para ejercer una profesión. En la lógica de la jerarquía social y los méritos, para ser médico o docente, se necesita cursar estudios en escuelas especializadas. En el territorio zapatista, se forman yerberas, hueseras y parteras para atender la salud de los habitantes. 
Para educar, se capacitan a promotores y promotoras, sin importar los grados académicos. El único requisito es que sepan leer y escribir, más la lengua de la comunidad y el español. La jerarquía se anula con la negación de la diferenciación, y la meritocracia se sustituye por la voluntad.

La educación zapatista no la viven las comunidades como un fetiche para curar todos los males sociales. A diferencia del discurso en boga de cualquier gobierno neoliberal que centra en la educación de calidad (lo que esto signifique) la solución a sus problemas, en la experiencia zapatista es una parte de la resistencia política, económica, cultural e ideológica. La educación autónoma se enlaza con el autogobierno, la autogestión de los proyectos de producción colectivos, el fortalecimiento de la identidad y la creación de sus medios de difusión. En medio de carencias materiales avanzan en los procesos de emancipación ideológica y de consolidación de su democracia desde abajo. Para esto no son indispensables las computadoras, los cañones y las presentaciones en Power Point. Tampoco las mesas redondas en las aulas, de moda por el constructivismo de Piaget, ni las paredes bien pintadas, porque su problema es político, no de infraestructura.

El desarrollo de la escuela zapatista continúa porque es una demanda de su levantamiento incluida en los acuerdos de San Andrés. Éstos firmados en 1996 con una comisión de negociación con el gobierno federal para solucionar el conflicto armado, pero que no fue avalado por el expresidente Ernesto Zedillo. En consecuencia, no se legisló el derecho de las comunidades indígenas de implantar una educación de acuerdo con su cultura y cosmovisión. Por otra parte, se creó la Ley de Concordia y Pacificación en noviembre de 1996 para garantizar el tránsito por el país de integrantes del EZLN, mientras lo hicieran desarmados y sin convocar a la violencia.

En este marco, el EZLN organizó su educación en dirección contraria a los planes del Estado mexicano. Como se citó en el Plan Sectorial de educación 2013-2018, la educación oficial aspira a formar sujetos con mentalidad empresarial.
Además, en 2017 difundió un modelo educativo para la educación básica que incluye al bachillerato. Se privilegia el uso de las tecnologías de la información y comunicación en el aula; también el aprendizaje a lo largo de la vida para reciclar la fuerza de trabajo según las exigencias de la esfera de la producción. En el modelo aludido los contenidos relevantes se refieren a: la educación financiera, la programación, la robótica y habilidades para emprender (Secretaría de Educación Pública 2017, p. 76). Como si no hubiera un contexto de especulación financiera, la sustitución del trabajo humano por la robótica y la automatización, más el aumento del empleo precario, el gobierno reproduce los contenidos sugeridos por los organismos financieros internacionales. La educación continúa viéndose desde un enfoque instrumental al servicio de la producción y el empleo (Silva, 2016). No obstante, el presidente electo, Andrés Manuel López Obrador, manifestó su oposición a la educación neoliberal. Se comprometió a mejorar las condiciones laborales del magisterio, aumentar la matrícula en educación superior y las becas en el bachillerato. Pero en el contexto de los gobernantes no existe la educación autónoma ni emancipadora, sino solo el supuesto desarrollo nacional.

Por tanto, la escuela zapatista no sigue la senda de convertirse en un aparato de Estado, porque la crean, recrean y conducen los integrantes de la comunidad. No propaga un discurso de dominación ni de obediencia del poder político o económico. Es su proceso no desean imponer, sino convencer. El nexo educación-producción no se orienta a forjar mano de obra asalariada, sino al desarrollo de la colectivización del campo, la constitución de cooperativas y tiendas comunales. En sus necesidades, estudiantes y promotores trabajan en la milpa para cosechar alimentos de autoconsumo. Así colaboran para la manutención en las secundarias que son albergues.

Es conveniente retomar el sentido del artículo: la educación zapatista como un movimiento de resistencia a las políticas educativas excluyentes de la globalización neoliberal. Es el intento de la construcción de una escuela anti- 
sistémica, porque no responde a la lógica de los rankings, la eficiencia terminal y la vinculación con el empleo. Sin certificaciones ni calificaciones se forma para servir a la comunidad, no a los empleadores. En este sentido, las dificultades de la escuela zapatista se concentran en la infraestructura y los recursos para mantenerlas, no tanto en su filosofía educativa y sus fines autonómicos. Sin embargo, las y los promotores de educación han afrontado las burlas del profesorado oficial que se infiltra en las zonas zapatistas y los acusa de no saber enseñar. El efecto es la renuncia de promotoras y promotores a su encargo (EZLN, s.f.b). También enfrentan la pérdida de la lengua materna porque las escuelas oficiales promueven el idioma inglés. Para contrarrestar esta situación se refuerza la enseñanza del tojolabal, tzetal o tzotzil. O la inequidad de las mujeres como responsables del impulso a la educación. Baronnet (2011b) registra que los promotores reconocen su falta de formación pedagógica $y$, en ocasiones, usan métodos de alfabetización ineficaces y tediosos, pero también son críticos de su práctica. En la ranchería Emiliano Zapata un promotor se quiere retirar porque necesita más apoyo y participación colectiva para realizar su labor. Otro problema es el incumplimiento de personas de la comunidad para aportar la ayuda en alimentos y leña; y aunque si hay colaboración del pueblo para trabajar la milpa, no siempre alcanza, en consecuencia, algunos promotores no pueden combinar la docencia y el cultivo agrícola.

En suma, el anhelo educativo del movimiento zapatista es una experiencia que se renueva para no institucionalizarse. De la escuela capitalista y occidental cambiaron radicalmente los contenidos, la idea de ser humano y sociedad. Aunque aplican exámenes de opción múltiple para conocer los aprendizajes, no se califica y no reproducen la lógica de la diferenciación y las recompensas, como las becas. Hasta el momento, tampoco hay una certificación oficial y demuestra que la educación no es tarea exclusiva de instituciones especializadas. Se avizora que se respeta la autonomía del estudiante. Ojalá que su escuela no se convierta en rígida, burocrática ni normalizada como la experiencia heredada de la modernidad.

Por el momento, en la escuela zapatista se enseña a contracorriente del pensamiento hegemónico global. Pareciera que se educa para lo inexistente. Por ejemplo, que para transformar la sociedad no es indispensable tomar el poder formal del Estado. O construir un gobierno sin políticos profesionales, con cargos rotativos y sin cobrar por ejercerlos, buscando erradicar la división entre quienes mandan y quienes obedecen para alcanzar procesos autogestivos (Castellanos, 2008). O la renuncia a toda vanguardia para que en la vida cotidiana la comunidad defina su identidad, viva el mandato y la democracia desde abajo, forjando el autogobierno bajo el principio de "mandar obedeciendo" y el ser colectivo. ¿Cómo enseñar ¡Para todos todo, nada para nosotros! (EZLN, 1995, parr. 18) en un mundo egoísta y utilitarista? A esto aspira la educación zapatista.

\section{Notas}

1 Es una forma de gobierno en las comunidades bajo el principio de mandar obedeciendo. El pueblo decide y los representantes realizan las acciones del pueblo; no se paga por gobernar, ni se reciben privilegios, los cargos son rotativos y colectivos. Siempre hay una mujer como representante en la JBG.

\section{Referencias bibliográficas}

Adamovsky, E. et al. (2011). Problemas de la política autónoma: pensando el pasaje de lo social a lo político. En E. Adamovsky et al. (Eds.), Pensar las autonomías. Alternativas de emancipación al capital y el Estado (209237). Distrito Federal, México: Bajo Tierra Ediciones-Sísifo Ediciones.

Althusser, L. (2003). Ideología y aparatos ideológicos del Estado. Freud y Lacan. Buenos Aires: Ediciones Nueva Visión.

Apple, M. (1997). Teoría crítica y educación. Buenos Aires: Miño y Dávila Editores. 
Baronnet, B. (julio, 2010). Zapatismo y educación autónoma: de la rebelión a la dignidad indígena. Sociedade e Cultura, 13(3), 247-258.

Baronnet, B. (abril, 2011a). Autonomía educativa zapatista: hacia una pedagogía de la liberación india en Chiapas. Em Aberto, Brasília, 24(85), 127-144.

Baronnet, B. (2011b). Entre el cargo comunitario y el compromiso zapatista. Los promotores de educación autónoma en la zona Selva Tseltal. En B. Baronnet, M. Mora \& R. StahlerSholk, (Eds.), Luchas "muy otras": Zapatismo $y$ autonomía en las comunidades indígenas de Chiapas (195-235). Distrito Federal, México: UAM-CIESAS-UACH.

Baronnet, B. (enero, 2015). Derecho a la educación y autonomía Zapatista en Chiapas, México. Convergencia 22(67) Recuperado de https:// goo.gl/x6z9bz

Castellanos, L. (2008). Corte de Caja. Entrevista con el Subcomandante Marcos. Distrito Federal, México: Endira-Bola de Cristal.

Centro de Español y Lenguas Mayas Rebelde Autónomo Zapatista (s.f.). Recuperado de https://goo.gl/bM8TpW

Ejército Zapatista de Liberación Nacional (1994). Primera Declaración de la Selva Lacandona. Recuperado de https://goo.gl/ZN5LbQ

Ejército Zapatista de Liberación Nacional (1995). Tercera Declaración de la Selva Lacandona. Recuperado de https://goo.gl/X4GQXF

Ejército Zapatista de Liberación Nacional (s.f. a). Gobierno Autónomo II. Cuaderno de texto de primer grado del curso de "La libertad según 1@s Zapatistas”, s. p.i.

Ejército Zapatista de Liberación Nacional (s.f. b). Resistencia Autónoma. Cuaderno de texto de primer grado del curso de "La libertad según 1@s Zapatistas", s. p.i.

Feire, P. (1997). Pedagogía de la autonomía. Distrito Federal, México: Siglo XXI Editores.

Giroux, H. (1992). Teoría y resistencia en educación, una pedagogía para la oposición (2a ed.). Distrito Federal, México: Siglo XXI EditoresCISE.

Giroux, H. (1997). Los profesores como intelectuales. Hacia una pedagogía crítica del aprendizaje. Barcelona: Páideos-M.E.C.
Gómez, M., \& Puiggrós, A. (1986). La Educación Popular en América latina 2. Distrito Federal, México: Ediciones Caballito-SEP.

Hijar, C. (2008). Autonomía Zapatista. Otro mundo es posible. México, Distrito Federal: AMV.

Illich, I. (1989). Un mundo sin escuelas. México, Distrito Federal: Nueva Imagen.

Jörgensen, M. (1997). Una escuela para la democracia. El instituto experimental de Oslo. Madrid: Laertes.

Lapassade, G. (1977). Autogestión pedagógica. Madrid: Gedisa.

López, F. (2011). Las autonomías indígenas en América Latina. En E. Adamovsky et al. (Eds.), Pensar las autonomías. Alternativas de emancipación al capital y el Estado (67102). Distrito Federal, México: Bajo Tierra Ediciones-Sísifo Ediciones.

Maldonado, C. E. (2016). El capitalismo académico: las universidades como entidades del mercado y mercadeo. Crítica $\mathrm{Cl}, 20$. Recuperado de https://goo.gl/xCAyg5

Marcos, S. (2003). Chiapas: la treceava estela. Quinta parte: una historia. Recuperado de https:// goo.gl/CpNXXE

Marx, C. (1986). Crítica del Programa de Gotha. Moscú: Editorial Progreso.

Marx, C., \& Engels, F. (1985). Manifiesto del Partido Comunista. Moscú: Editorial Progreso.

Moisés, S. (2013). Fechas y otras cosas para la escuelita zapatista. Recuperado de https://goo.gl/ plgGQe

Muñoz, G. (septiembre, 2004). Los caracoles: reconstruyendo la nación. Rebeldía 2(23), 3-24.

Revelli, M. (noviembre, 2004). La nueva palabra zapatista. Rebeldía, 2(25), 33-41.

Secretaría de Educación Pública (2013). Programa Sectorial de Educación 2013-2018. Distrito Federal, México: SEP.

Secretaría de Educación Pública (2017). Modelo Educativo para la educación obligatoria. Educar para la libertad y creatividad. Versión PDF.

Silva, C. (2016). Currículo basado en competencias en el bachillerato mexicano: El enfoque unidimensional hacia el mercado. Ciudad Juárez: UACJ. 
Silva, C. (2018). Perfil de egreso y empleo en el contexto del avance tecnológico. Revista Pedagogía y Saberes, (48), 83-96.

Torres, I. (2012). La nueva educación zapatista: Formación de una identidad diferenciada en los niños de las comunidades autónomas zapatistas. Revista Divergencia, 1(2), 135-160.

Tyack, D., \& Cuban, L. (2001). En busca de la utopía.

Un siglo de reformas de las escuelas públicas
( $2^{\text {a }}$ ed.). Distrito Federal, México: Fondo de Cultura Económica.

Vaughan, M. K. (1997). El cambio ideológico en la política educativa de la SEP: Programas y libros de texto, 1921-1940. En Susana Quintanilla (Ed.), Escuela y sociedad en el periodo Cardenista (76-108). Distrito Federal, México: FCE. 